\title{
Experience and Cost of Pediatric Gastroenteritis to Families: A Survey of Malaysian and Vietnamese Parents
}

\author{
Azmi $S^{1,2 *}$ and Reginald $\mathrm{P}^{1,2}$ \\ ${ }^{1}$ Veras Research, Petaling Jaya, Selangor, Malaysia \\ ${ }^{2}$ Azmi Burhani Consulting, Petaling Jaya, Selangor, Malaysia
}

Received: December 16, 2014; Accepted: February 18, 2015; Published: February 20, 2015

*Corresponding author: Soraya Azmi, Managing Director, Veras Research, Metropolitan Square, W103A, Jalan PJU 8/1, Damansara Perdana, 47820 Petaling Jaya, Selangor, Malaysia, Tel: +6-03-7725 7500; Fax: +6-03-7733 7510; E-mail: soraya.azmi@verasresearch.com

\begin{abstract}
Objective: Similar to other parts of the world, gastroenteritis is an important cause of morbidity among children in South East Asia. We conducted a study to better understand the experience of pediatric gastroenteritis families from a parental perspective in Malaysia and Vietnam. It is also to explore cost and productivity loss associated with pediatric gastroenteritis incurred by families.
\end{abstract}

Methods: A survey was conducted between August 2012 and April 2013 in Malaysia and Vietnam. A total of 245 and 307 questionnaires were completed by respondents selected by convenience sampling in Malaysia and Vietnam, respectively. A descriptive statistical analysis was performed.

Results: Among respondents who had children below the age of $10,89.6 \%$ of Vietnamese respondents and $98.8 \%$ of Malaysian respondents reported that their children had experienced an episode of gastroenteritis. Of these, $41.0 \%$ of Vietnamese parents and $21.1 \%$ of Malaysian respondents reported that the gastroenteritis episode required hospital admission. The most commonly reported length of hospitalization in Malaysia and Vietnam was 2 to 5 days. Overall, the most common hospitalization fees were more than USD 350 in Malaysia and between USD 1 to USD 34 in Vietnam. There were differences in the presentation of gastroenteritis and access to the health system was different in the two countries with different economic impact on families.

Conclusion: Overall, the majority of parents surveyed in both countries reported their children having experienced gastroenteritis. The episodes incurred a financial cost as well as productivity loss. There were several study limitations including the small convenience sample obtained and a lack of cost information to fully account for the economic costs. Nonetheless, the results offer some additional insight into the impact of childhood gastroenteritis on families in these two countries. Education on prevention is needed and vaccination should be considered.

Keywords: Pediatric gastroenteritis; Cost; Productivity loss; Parents

\section{Introduction}

Gastroenteritis is one of the leading causes of pediatric morbidity and mortality, worldwide [1-3]. In terms of causative organisms in children, approximately $70 \%$ episodes of gastroenteritis are caused by virus, followed by $10 \%$ to $20 \%$ by bacteria and less than $10 \%$ are due to protozoa [2,47]. The common causative organisms are rotavirus, nontyphoidal Salmonella, Campylobacter species, Shigella species and Escherichia coli [4-7]. Each year, an estimated two billion cases are reported globally with approximately 440,000 annual deaths, particularly affecting children below the age of five in developing countries $[1,8]$. Furthermore, gastroenteritis is the second most common cause of death in children in this age group after pneumonia [1]. Among the common causative organisms, rotavirus gastroenteritis causes approximately 111 million episodes of gastroenteritis per year requiring home care, 25 million clinic visits, and 2 million hospital admissions.

Studies in Asia have shown that rotavirus contributes 43\% to $60 \%$ of the diarrheal admissions in Vietnam, 32.9\% in Taiwan and 24 to $55 \%$ in Malaysia [11-13]. Young children between 6 months and 3 years old have been reported to have a higher prevalence rate of rotavirus gastroenteritis [12,14-15]. In terms of gastroenteritis in general, studies indicated that the peak incidence of gastroenteritis related hospital admissions in Malaysia occur in the rainy season [12], generally peaking at the beginning and end of each year [13] but the months may differ according to different studies.

Taking into consideration the economic burden and costs associated with gastroenteritis, studies conducted have tended to focus on rotavirus-associated gastroenteritis and this has been reported in several studies [9-10,16-17]. In Vietnam, annually, the economic burden of rotavirus gastroenteritis was estimated to be USD 3.1 million in medical costs, USD 685,000 in non-medical costs and USD 1.5 million in indirect costs [9]. In Malaysia, such an economic study has not been performed but a study by Chai and Lee estimated that the cost incurred associated with hospitalization for rotavirus gastroenteritis was USD 194 [18]. The direct medical costs per annum associated to rotavirus gastroenteritis was estimated at USD 10 to 16 million in Taiwan and USD 57 million in Japan [10,17]. In the larger context of developing countries, a study by Rheingans et al estimated the cost of rotavirus gastroenteritis in developing countries in general and the subsequent cost-effectiveness of rotavirus 
vaccination [19]. Within this context, Malaysia and Vietnam were classified as upper-middle-income countries respectively [19]. According to the Rheingans study, the cost-effectiveness of rotavirus vaccine at $\$ 7.50$ per dose was USD 291 and USD 329 per DALY in Vietnam and Malaysia, respectively [19].

Most studies on economic impact have focused on rotavirus infections. Yet, the economic impact of gastroenteritis specifically on families in South East Asia has not been reported thus far. In this study we consider South East Asia here as defined by the Association of South East Asian Nations which include Brunei, Cambodia, Indonesia, Laos, Malaysia, Myanmar, Philippines, Singapore, Thailand and Vietnam [20]. Within the wider Asian continent, a study conducted in United Arab Emirates had explored the impact of gastroenteritis [21]. The study was a survey among parents which found that an average of 1.4 days of work was missed by parents per episode of gastroenteritis [21] The study reported that $87 \%$ of parents had sought medical care for their affected children and $10 \%$ of cases required admission to hospital with an average length of stay of 2.6 days [21]. Furthermore, the average cost of a gastroenteritis episode to parents was USD 64 [21]. On the other hand, a study by Musawi et al. conducted in Bahrain focused on rotavirus infections reported a mean hospitalization duration of 4.1 days [22].

We conducted the present study to assess the impact of gastroenteritis as experienced by parents and evaluate the cost to families and productivity losses when their children have gastroenteritis. Malaysia and Vietnam were selected as two countries representing different South East Asian countries in our study. The two countries have some similarities and intercountry trade is common. However, there are also differences in terms of population size, language and economic development $[23,24]$

\section{Methods}

\section{Study design and setting}

This was a cross-sectional survey conducted over a period of 9 months between August 2012 to April 2013 in Hanoi and Bac Giang in Vietnam and in the Klang Valley, Malaysia. The survey targeted parents or caregivers with young children below the age of 10 . The survey was conducted using convenience sampling and the study participants were recruited in residential areas as well as public spaces.

\section{Data collection}

The questionnaire was prepared in English and in the Vietnamese language. The questionnaire contained a total of 22 questions encompassing socio-demographic details as well as the respondent's experience about their child's last gastroenteritis episode. This included the type of treatment, duration of hospitalization, cost of hospitalization, mode of payment of hospitalization fees and the number of days off from work to care for their child who was affected by gastroenteritis. Verbal consent was obtained from the respondents prior to completing the self-administered questionnaire.

\section{Data analysis}

Descriptive analysis was performed. For ease of comparison, the costs were converted from local currency units (MYR and VND) to US dollars (USD) based on the currency conversion rate in May 2013 (1 USD=3.06 MYR; 1 USD=20,964.60 VND).

\section{Results}

\section{Demographics}

Survey questionnaires were completed by 245 and 307 respondents from Malaysia and Vietnam, respectively. Table 1 presents the demographic information of the respondents. Among the total respondents, $92.0 \%$ of the total respondents (234 from Malaysia and 275 from Vietnam) were parents of children below the age of 10 . Of these, $72.8 \%$ of the total respondents were female rather than male. The majority of respondents from Malaysia (54.6\%) reported to have more than 5 children whereas majority of Vietnamese respondents (97.1\%) reported to have 1 or 2 children. The most common category of household income reported was USD 850 to USD 1749 (43.6\%) among Malaysian respondents while among Vietnamese respondents it was USD 350 to USD 849 (47.1\%).

\section{Clinical Presentation}

Collectively, vomiting and diarrhea were the more commonly Table 1: Demographic details of survey respondents.

\begin{tabular}{|c|c|c|}
\hline Country & $\begin{array}{l}\text { Malaysia } \\
\text { N (\%) }\end{array}$ & $\begin{array}{l}\text { Vietnam } \\
\mathrm{N}(\%)\end{array}$ \\
\hline $\begin{array}{l}\text { TOTAL RESPONDENTS } \\
\text { Gender } \\
\text { Male } \\
\text { Female }\end{array}$ & $\begin{array}{l}245(100.0 \%) \\
112(77.2 \%) \\
133(91.7 \%)\end{array}$ & $\begin{array}{l}307(100.0 \%) \\
38(12.4 \%) \\
269(87.6 \%)\end{array}$ \\
\hline $\begin{array}{l}\text { Age of respondents } \\
\text { Below } 20 \\
20-30 \\
31-40 \\
41-50 \\
51 \text { and over }\end{array}$ & $\begin{array}{l}0(0.0 \%) \\
87(35.5 \%) \\
124(50.6 \%) \\
28(11.4 \%) \\
6(2.4 \%)\end{array}$ & $\begin{array}{l}1(0.3 \%) \\
157(51.3 \%) \\
137(44.8 \%) \\
8(2.6 \%) \\
3(1.0 \%)\end{array}$ \\
\hline $\begin{array}{l}\text { Parents of children below age of } 10 \\
\text { Yes } \\
\text { No }\end{array}$ & $\begin{array}{l}234(95.6 \%) \\
11(4.5 \%)\end{array}$ & $\begin{array}{l}275(89.6 \%) \\
32(10.4 \%)\end{array}$ \\
\hline $\begin{array}{l}\text { Number of children } \\
1-2 \text { children } \\
3-4 \text { children } \\
5 \text { or more children }\end{array}$ & $\begin{array}{l}70(20.2 \%) \\
87(25.1 \%) \\
189(54.6 \%)\end{array}$ & $\begin{array}{l}267(97.1 \%) \\
8(2.9 \%) \\
0(0.0 \%)\end{array}$ \\
\hline $\begin{array}{l}\text { Monthly household income } \\
\text { None } \\
\text { Less than USD } 350 \\
\text { USD 350-849 } \\
\text { USD 850-1749 } \\
\text { USD 1750-3499 } \\
\text { USD 3500 and above }\end{array}$ & $\begin{array}{l}27(11.1 \%) \\
8(3.3 \%) \\
60(24.7 \%) \\
106(43.6 \%) \\
39(16.1 \%) \\
3(1.2 \%)\end{array}$ & $\begin{array}{l}1(0.3 \%) \\
134(43.8 \%) \\
144(47.1 \%) \\
25(8.2 \%) \\
1(0.3 \%) \\
1(0.3 \%)\end{array}$ \\
\hline $\begin{array}{l}\text { Employer type } \\
\text { Government } \\
\text { Private company } \\
\text { Own business } \\
\text { Not working }\end{array}$ & $\begin{array}{l}62(25.5 \%) \\
102(42.0 \%) \\
51(21.0 \%) \\
28(11.5 \%)\end{array}$ & $\begin{array}{l}148(48.5 \%) \\
94(30.8 \%) \\
56(18.4 \%) \\
7(2.3 \%)\end{array}$ \\
\hline
\end{tabular}


experienced symptoms during a gastroenteritis episode (Figure 1). In Vietnam, majority of the respondents reported that diarrhea was the most common symptom experienced, $74.8 \%$ during clinic visits and $78.0 \%$ during hospitalization (Figure 1). On the other hand, Malaysian respondents reported that the common symptom experienced was vomiting, $81.0 \%$ during clinic visits and $82.4 \%$ during hospitalization (Figure 1).

In addition to that, our study also found a percentage of gastroenteritis reported among children aged from 0 to 5 years old in both countries surveyed (Figure 2). In Malaysia, 63.3\% of the respondents reported that their child who had gastroenteritis was between 0 to 1 year followed by $33.2 \%$ reporting that their child had gastroenteritis between the ages of 1 to 2 years old and only a minority of respondents reported gastroenteritis episode between age group of 2 to 5 years or above (Figure 2). In contrast, in Vietnam, the proportion of reported gastroenteritis was more commonly reported in children aged between 2 to 5 years old $(38.5 \%)$ and less than 1 year of age (36.3\%) (Figure 2).

\section{Clinic Visit and Hospitalization}

Overall, $143(52.0 \%)$ of respondents in Vietnam, and 216 (89.3\%) respondents in Malaysia reported that their child had experienced gastroenteritis in the past requiring a visit to the clinic (Figure 3). In addition to that, $41.0 \%$ of respondents in Vietnam and $21.1 \%$ of respondents in Malaysia reported gastroenteritis episodes requiring admission to hospital (Figure 3).

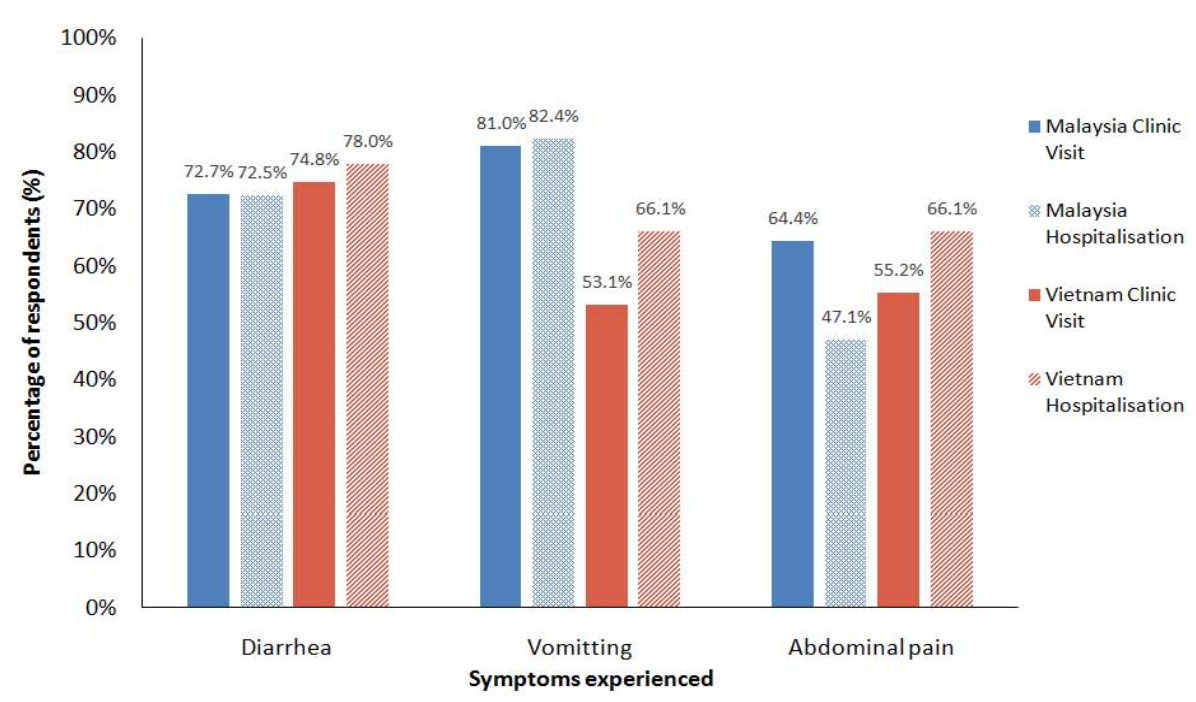

Figure 1: The symptoms experienced during a clinic visit or hospitalization reported by survey respondents in Malaysia and Vietnam.

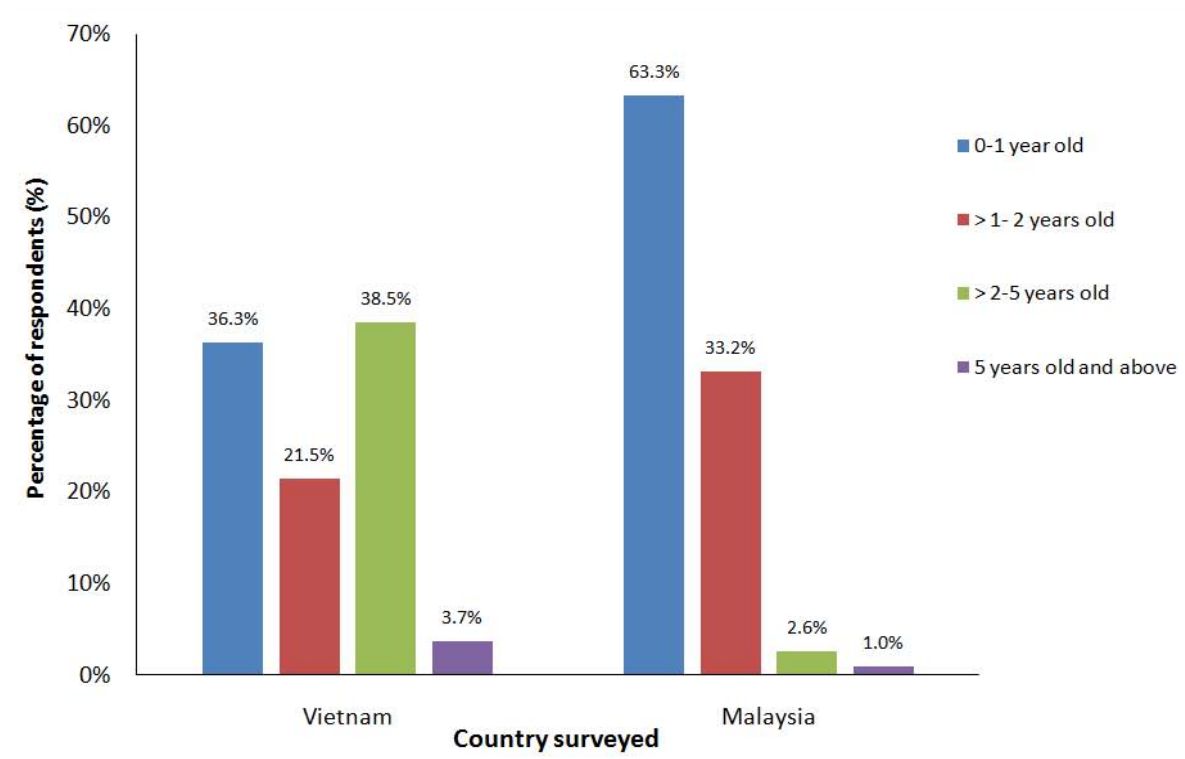

Figure 2: The age range of children during gastroenteritis episode reported by survey respondents in Malaysia and Vietnam. 


\section{Type of hospital}

A majority of respondents in Vietnam, 96.6\% reported that their child was admitted to public hospitals (data not shown). On the other hand, an almost equal distribution of Malaysian respondents reported admissions to public (51.0\%) or private (49.0\%) hospitals (data not shown).

\section{Duration of hospital admission}

On average, most survey respondents $(76.5 \%$ from Malaysia and $67.8 \%$ from Vietnam) reported the length of stay in hospital between 1 to 5 days (Figure 4). This was followed by $23.5 \%$ and 27.1\% reporting 6 to 10 days of hospital admission in Malaysia and Vietnam, respectively. Furthermore, $5.1 \%$ of Vietnamese respondents reported admissions of more than 11 days while no Malaysian respondents reported hospital admissions of more than 10 days (Figure 4).

\section{Hospitalization fees}

In terms of the fees charged for gastroenteritis associated hospitalization, the majority of Malaysian respondents (41.2\%) reported paying more than USD 350 whereas the most common fee category reported by Vietnamese respondents (45.9\%) was USD 1 to USD 34 (Figure 5). Overall, the fee charged for admission to public hospital due to pediatric gastroenteritis was USD 1 to USD 34 in both countries (data not shown). In contrast, the common gastroenteritis associated hospitalization fee charged by private hospitals in Malaysia was more than USD 350 (data

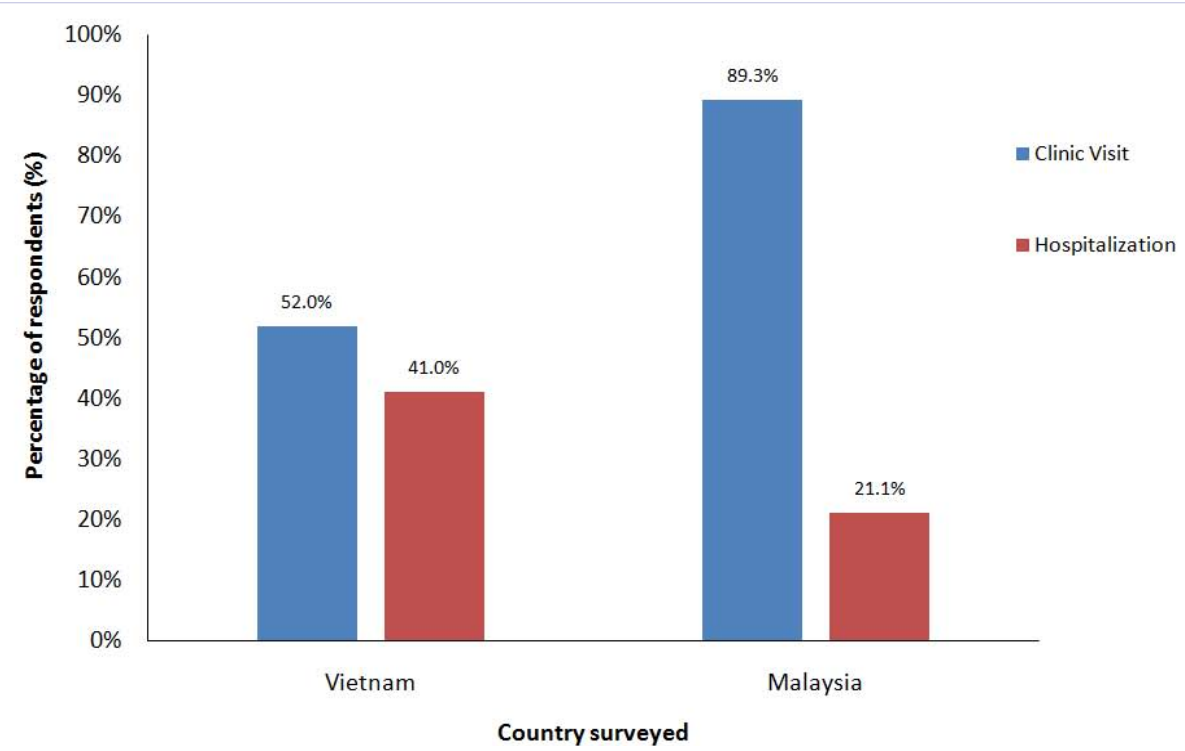

Figure 3: Clinic visit or hospitalization due to pediatric gastroenteritis reported by survey respondents in Malaysia and Vietnam.

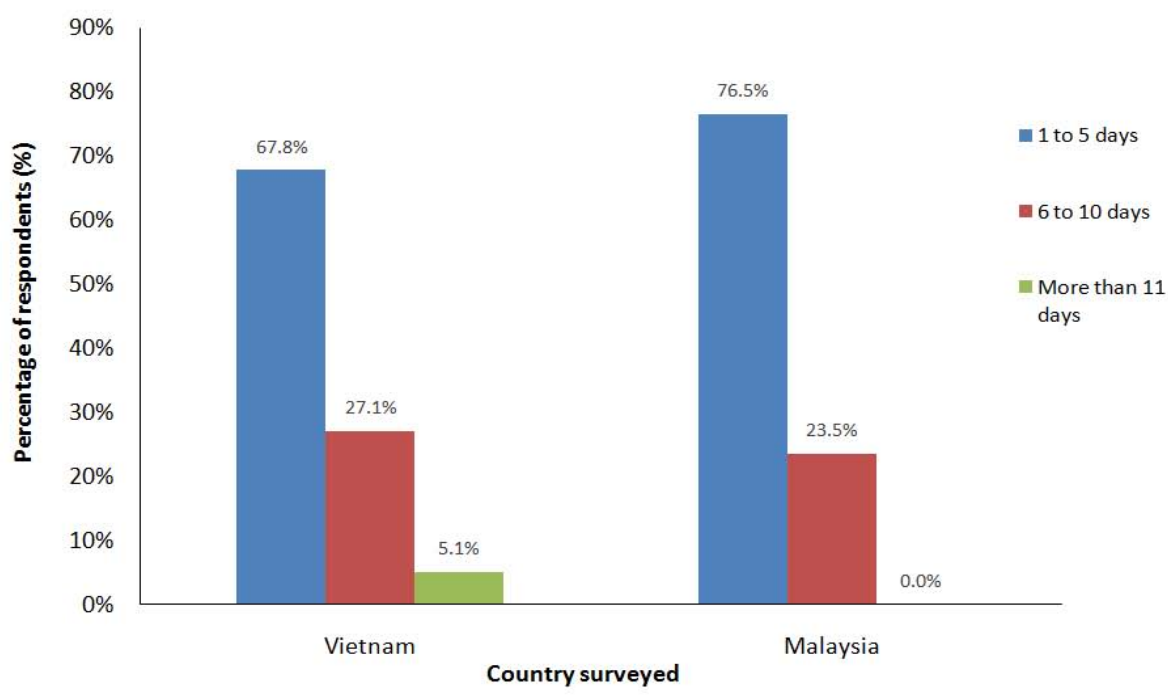

Figure 4: Length of hospital admission reported by survey respondents in Malaysia and Vietnam. 
not shown). In Vietnam, this remained unchanged at USD 1 to USD 34 (data not shown)

\section{Time away from work}

The majority of the respondents, $47.5 \%$ from Vietnam and $56.9 \%$ from Malaysia reported taking 2 to 5 days off from work to care for their affected child (Figure 6). Respondents in Malaysia (3.9\%) reported that they spent up to 10 days while some respondents in Vietnam (3.4\%) reported that they needed more than 10 days away from work to care for their affected child (Figure 6).

\section{Discussion}

We found that there were greater differences than similarities observed. One similarity was that the age range of children affected by gastroenteritis was usually between 0 to 2 years old. This was consistent with the common age range reported in the previous studies in Malaysia, 6 to 17 months [12] and in Vietnam, 13 to 24 months [25]. Another similarity observed was in the days taken off from work by parents or caregivers when their children had gastroenteritis. The majority of parents from both countries reported 2 to 5 days away from work to care for their sick child. This number of days is similar to that found by Howidi

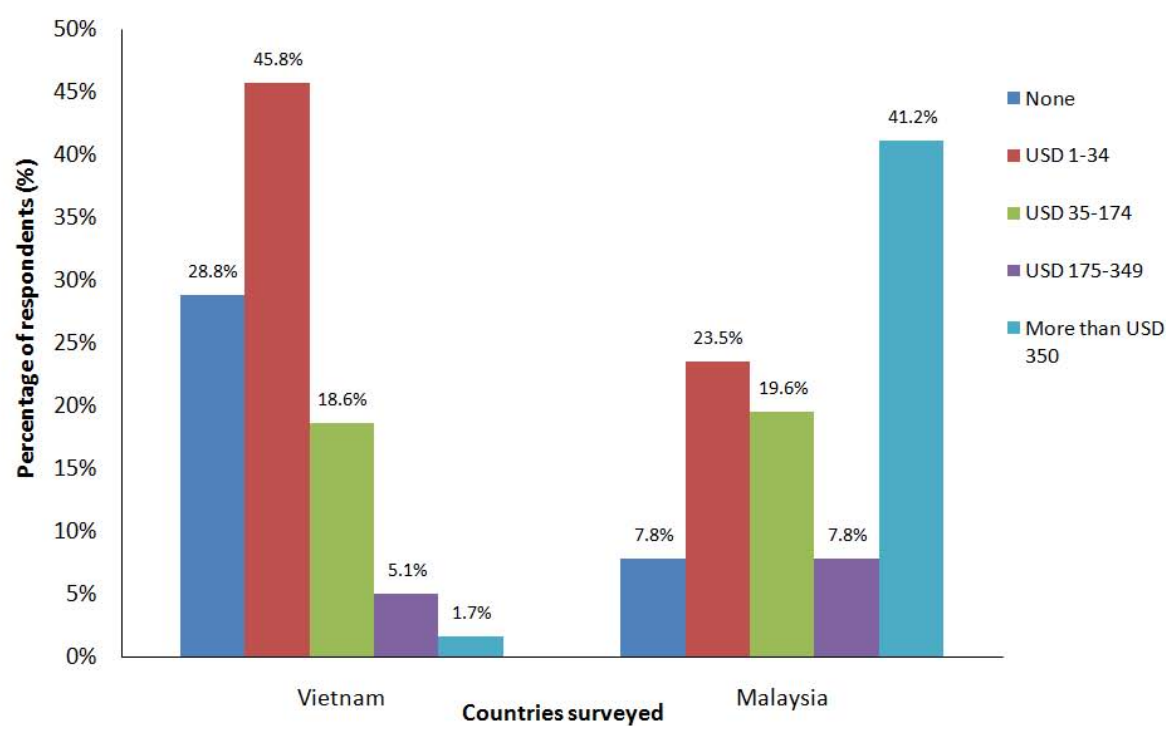

Figure 5: Fees paid for hospitalization reported by survey respondents in Malaysia and Vietnam.

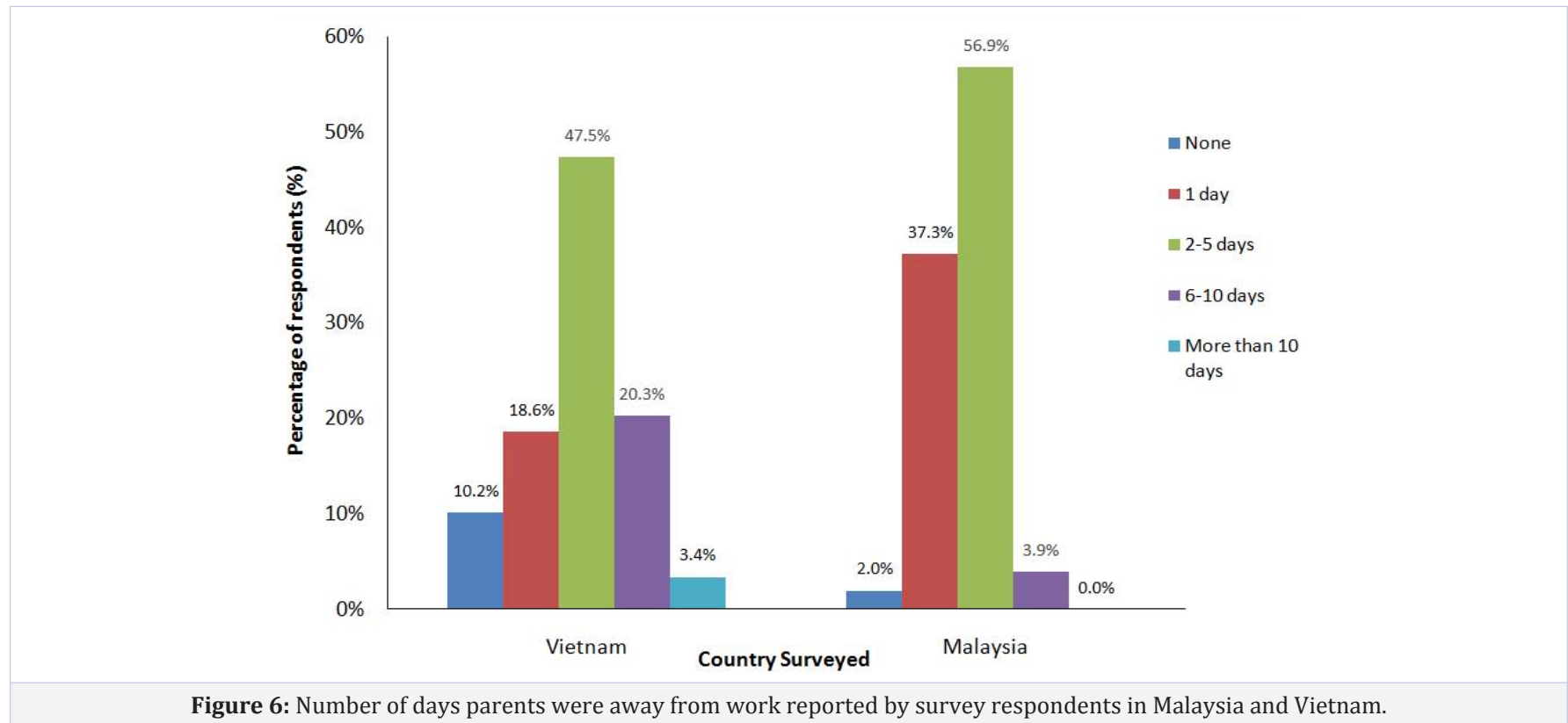

Citation: Azmi S, Reginald P (2015) Experience and Cost of Pediatric Gastroenteritis to Families: A Survey of Malaysian and 


\section{et al in the United Arab Emirates as mentioned above [21].}

There were differences in terms of the presentation of gastroenteritis as reported by parents was treatment seeking patterns, type of hospital and the length of hospitalization associated with pediatric gastroenteritis between Vietnam and Malaysia. A greater proportion of respondents in Malaysia reported their child required a clinic visit compared to hospital admission. In contrast, hospital admissions due to gastroenteritis were more common in Vietnam. The Malaysian findings corroborate with findings by Poo et al who reported that $77 \%$ of the patients recruited for a hospital gastroenteritis study had sought a clinic visit before hospitalization [26]. Related to duration of admission, some respondents in Vietnam reported needed more than 10 days away from work whereas none reported this in Malaysia. We speculate that due to socioeconomic circumstances or other reasons, a child's condition in Vietnam may be more severe at the time they are admitted into the hospital. The reason for this difference could not otherwise be elucidated from the survey and may be investigated further in a future study.

On the other hand, we also noted some differences in the access to the health system in the two countries surveyed. From the data collected, we observed that public hospital admissions were more common in Vietnam compared to Malaysia. This is an interesting finding considering that public hospitals are widespread throughout Malaysia providing highly subsidized care. This could be due to a lack of representativeness of our sample. And yet, it may also raise the possibility that when it comes to care of their children, parents are willing to pay for what is perceived as higher quality or greater comfort and hence opt for the private care despite the higher cost to them. The length of hospitalization was similar in both countries with the greatest proportion of respondents reporting that their child was hospitalized for 1 to 5 days. A recent study by Goh et al performed in a tertiary hospital in Sabah, Malaysia also reported similar common range of hospitalization duration, between 1 to 6 days [27]. This length of time is significant considering that in many cases both parents may be working. As well, due the large number of people working in the informal sector or working for daily wages in these two countries, the loss of a week's work could be a significant burden on a family's income. In Malaysia, the percentage of people working in the informal sector varies from less than $10 \%$ in some states up to approximately $15 \%$ [28] In Vietnam, this is estimated to be as high as $82 \%$ [29]. Therefore, the impact of the number of days spent not working may have worse impact on families in Vietnam if there are more parents earning daily wages.

We found a significant variation in the hospitalization fee charges for gastroenteritis-associated hospital admission in children in Malaysia and Vietnam. The current study observed that the cost of hospitalization per episode was significantly lower in Vietnam compared to Malaysia. Related to this, it was observed that the majority of the parents or caregivers in Malaysia paid more than USD 350 in hospitalization fees per episode whereas the average hospitalization fee in Vietnam was only between USD 1 to USD 34. For Vietnam, our findings are similar to a study by Fischer et al in 2004 which reported that the estimated costs of diarrheal disease in Vietnam was USD 36 [9]. For Malaysia, the cost reported is slightly higher than prospective study by Chai in 2007 in a single academic center which showed that the estimated outof-pocket expenditure incurred by caregivers for an admission to hospital due to rotavirus caused gastroenteritis was USD 194 [18]. This is likely due to the large number of survey respondents reporting their child was admitted to a private hospital. On the other hand, we note that Malaysian respondents receiving public hospital care reported hospitalization fees less than USD 34 only which is similar to that reported by Vietnamese parents in our survey and lower than that reported by Chai. This point can be explained since academic centre fees are generally slightly higher than that charged by Ministry of Health hospitals and lower than that of private hospitals. It is important to reiterate here that our study is intended to report the fees paid by parents as users of the healthcare system. The fees charged by government run hospitals, including academic settings, are greatly subsidized by the governments of both countries [30,31].

There were some recognized limitations in our study. Firstly, this was an exploratory survey and respondents were recruited using a convenience sampling method. Furthermore, the total number of respondents recruited was small. Hence, our survey participants cannot be considered representative of all parents of the two countries. Besides that, our survey data was based on the respondent's recall of their child's most recent gastroenteritis episode. We collected categorical data to ease recall but this has its inherent limitations. In addition, there would have been disruption to other family activities and care of other children in the family particularly with the occurrence of a hospital admission. Additional family helpers may have had to be called to assist with family responsibilities while parents accompanied their child during admission. This cost was not taken into account in our survey. Aside from methodological issues, there were also important differences in the income level, healthcare system variation and possibly cultural differences between the two countries which may explain our findings.

Despite these limitations, findings from our study may provide useful insights into the experience of gastroenteritis from the parental perspective. Out-of-pocket costs incurred, time away from work and the related potential loss of income are important factors to consider. Our study may also have indicated that parents are willing to pay the higher private hospitals fees, at least in Malaysia, to obtain treatment for their child despite its cost. This study highlights that despite economic development in these two countries, gastroenteritis still has significant impact on families. We hope that the findings from our study help to add impetus to a commitment to better educate parents on improving hygiene and preventing childhood gastroenteritis. Simple steps like maintenance of oral hydration through consumption of liquids during an episode of gastroenteritis should be stressed to parents. For instance, breastfeeding infants should continue 
to breastfeed and older children should be coaxed to drink sips of water more frequently [32]. As rotavirus is one of the most common pathogens causing acute gastroenteritis, vaccination should be considered as a means to reduce the impact on families if the vaccination costs are within affordable reach [19].

\section{Conclusion}

In conclusion, gastroenteritis still continues to have a great impact on families even in the urban parts of Malaysia and Vietnam. A large majority of surveyed parents had experience of gastroenteritis in their child. Furthermore, $41.0 \%$ of Vietnamese parents and $21.1 \%$ of Malaysian parents reported that their child's condition required a hospital admission and a parent needed 2 to 5 days off from work to care for the sick child. There were expected variations observed in the hospitalization costs between the two countries surveyed due to differences in health care systems. Despite the limitations in our study, we believe that our study shows the important economic impact of childhood gastroenteritis on families. This calls for greater attention to prevention including education and vaccination.

\section{Acknowledgements}

The authors would like to thank Ngo Thi Thao, Nguyen Thi Thanh Tam and Gayathri Arumugham for conducting the surveys and Chong Hor Yan and Ainil Hawa Mohamed for their support and assistance.

\section{Conflict of Interest}

The authors declared that there are no funding to disclose or conflict of interest with respect to this manuscript.

\section{References}

1. WHO. Diarrhoeal disease. Available from: http://www.who.int/ mediacentre/factsheets/fs330/en/.

2. Elliott EJ. Acute gastroenteritis in children. BMJ. 2007;334:17204802. doi:10.1136/bmj.39036.406169.80.

3. Parashar UD, Bresee JS, Gentsch JR, Glass RI. Rotavirus. Emerg Infect Dis. 1998; 4: 9866732.

4. Iyngkaran N, Abidin Z, Lam SK, Puthucheary SD. Acute gastroenteritis in Malaysian children: aetiological and therapeutic considerations. Med J Malaysia. 1980; 34: 7219272.

5. Koe SL, Tay LK, Puthucheary SD, Lam SK. Infectious agents causing diarrhoea in Malaysian children. Malaysian J Child Health. 1991; 1329; 29-33.

6. Szajewska H, Dziechciarz P. Gastrointestinal infections in the pediatric population. Curr Opin Gastroenterol. 2010; 26: 19887936. doi:10.1097/MOG.0b013e328333d799.

7. Lee WS, Puthucheary SD. Bacterial enteropathogens isolated in children with acute gastroenteritis in Kuala Lumpur-a changing trend. Medical Journal of Malaysia. 2002; 57.

8. Parashar UD, Gibson CJ, Bresee JS, Glass RI. Rotavirus and severe childhood diarrhea. Emerging Infect Dis. 2006;12:16494759. doi:10.3201/eid1202.050006.
9. Fischer TK, Anh DD, Antil L, Cat NDL, Kilgore PE, Thiem VD, et al. Health care costs of diarrheal disease and estimates of the cost-effectiveness of rotavirus vaccination in Vietnam. J Infect Dis. 2005;192:16235169. doi:10.1086/497339.

10. Lu CY, Lauderdale TL, Fang YH, Wang CY, Ho YH, Hung CL, et al. Disease burden and related medical costs of rotavirus infections in Taiwan. BMC Infect Dis. 2006; 6: 17173677. doi: 10.1186/1471-2334- 6-176.

11. Yap KL, Yasmin AM, Wong YH, Ooi YE, Tan SC, Jegathesan M, et al. A one year community-based study on the incidence of diarrhoea and rotavirus infection in urban and suburban Malaysian children. Med J Malaysia. 1992; 47: 1303484

12. Hung LC, Wong SL, Chan LG, Rosli R, Ng ANA, Bresee JS. Epidemiology and strain characterization of rotavirus diarrhea in Malaysia. Int J Infect Dis. 2006; 10: 17046306. doi:10.1016/j.ijid.2006.05.008.

13. Lee WS, Veerasingam PD, Goh AYT, Chua KB. Hospitalization of childhood rotavirus infection from Kuala Lumpur, Malaysia. J Paediatr Child Health. 2003;39:12969206.

14. Cheah WL, Lee PY, Syed Alwi SAR, Kamarudin K, Albela H, Lau EH, et al. Acute gastroenteritis among indigenous paediatric patients - A descriptive study in a rural district hospital, Sarawak. Malaysian J Med Health Sciences. 2011; 7(2): 3-7.

15. Doan LTP, Okitsu S, Nishio O, Pham DT, Nguyen DH, Ushijima H. Epidemiological features of rotavirus infection among hospitalized children with gastroenteristis in Ho Chi Minh City, Vietnam. J Med Virol. 2003; 69: 12601768. doi:10.1002/jmv.10347.

16. Jin H, Wang B, Fang Z, Duan Z, Gao Q, Liu N, et al. Hospital-based study of the economic burden associated with rotavirus diarrhea in eastern China. Vaccine. 2011;29:21843578. doi:10.1016/j. vaccine.2011.07.104.

17. Ito H, Otabe O, Katsumi Y, Matsui F, Kidowaki S, Mibayashi A, et al. The incidence and direct medical cost of hospitalization due to rotavirus gastroenteritis in Kyoto, Japan, as estimated from a retrospective hospital study. Vaccine. 2011; 29: 21821087. doi:10.1016/j. vaccine.2011.07.105.

18. Chai PF, Lee WS. Out-of-pocket costs associated with rotavirus gastroenteritis requiring hospitalization in Malaysia. Vaccine. 2009; 27 Suppl 5: 19931708. doi:10.1016/j.vaccine.2009.08.069.

19. Rheingans RD, Antil L, Dreibelbis R, Podewils LJ, Bresee JS, Parashar UD. Economic costs of rotavirus gastroenteritis and cost-effectiveness of vaccination in developing countries. J Infect Dis. 2009; 200 Suppl 1: 19817595. doi:10.1086/605026.

20. Association of Southeast Asian Nations. ASEAN Member States

21. Howidi M, Al Kaabi N, El Khoury AC, Brandtmüller A, Nagy L, Richer E, et al. Burden of acute gastroenteritis among children younger than 5 years of age--a survey among parents in the United Arab Emirates. BMC Pediatr. 2012;12:22708988. doi:10.1186/1471-2431-12-74.

22. Al Musawi M, Zainaldeen H, Shafi F, Anis S, DeAntonio R. Rotavirus gastroenteritis in children under 5 years in the Kingdom of Bahrain: hospital-based surveillance. Clinical Epidemiology. 2013. doi:10.2147/CLEP.S46822.

23. The World Bank Group. GDP per capita (current US\$). Available from: http://data.worldbank.org/indicator/NY.GDP.PCAP.CD.

24.Vietnam Overview n.d. http://www.worldbank.org/en/country/ vietnam/overview (accessed February 25, 2015). 
25. Nguyen TV, Le Van P, Le Huy C, Weintraub A. Diarrhea caused by rotavirus in children less than 5 years of age in Hanoi, Vietnam. J Clin Microbiol. 2004; 42:15583308. doi: 10.1128/JCM.42.12.5745- 5750.

26. Izzuddin Poo M, Lee WS. Admission to hospital with childhood acute gastroenteritis in Kuala Lumpur, Malaysia. Med J Malaysia. 2007;62:18246904.

27. Goh CT, Cheah PK, Soo TL, Lee WS. The epidemiology and burden of childhood rotavirus infection in a tertiary hospital in Sabah, Malaysia Med J Malaysia. 2009; 64: 20058575.

28. Nazaria B, Othman M, Che Pah PW, Chellamuthu D, Musa R. Informal employment in informal sector enterprises in Malaysia. Informal sector in Malaysia: 33-45.

29. Jean-Pierre C, Razafindrakoto M, Roubaud F. The informal economy in Viet Nam. Available from: http://www.ilo.org/wcmsp5/groups/ public/---asia/---ro-bangkok/---ilo-hanoi/documents/publication/ wcms_171370.pdf. (accessed November 27, 2014)

30. Merican MI, Rohaizat Y, Haniza S. Developing the Malaysian health system to meet the challenges of the future. Med J Malaysia. 2004;59:15535341.

31. Tran VT, Hoang TP, Inke M, Nguyen TKP. A health financing review of Vietnam with a focus on social health insurance. 2011: 1-46.

32. King CK, Glass R, Bresee JS, Duggan C. Managing acute gastroenteritis among children. Oral rehydration, maintenance, and nutritional therapy. CDC. Morbidity and Mortality Weekly Report. 2003; 52 (RR16); 1-16. 